value of its organisation and culture must be gauged by the manner in which it ministers to the wants of the individuals which constitute it. Here then are problems so absolutely foreign to the biological theory of natural selection as to preclude any borrowing by sociology from biology.

Mr. Soal's kind exhortation to anthropology that it should become " detached and objective," and that it should give up troubling about the " character of past or primitive societies," and study " prohibition or divorce reform " instead, will no doubt be humbly and hopefully received by other anthropologists as it is by the present writer; though I. fear that my experience in discussions about problems touching liquor and sex seems to show that they do not lead to an "objective or detached" frame of mind. In the attempt to follow his advice, we might realise Mr. Soal's " homely example" of an anthropologist appearing " in his class-room wearing a Malayan kris," a tendency of which he seems to suspect me. I do not think there is any hope, either, that the science of primitive man should give up studying primitive man, any more than that astronomers should give up studying stars, when advised to turn their attention to turnips and potatoes, since this "is more useful." BRONISLAw MALINOWSKI.

Department of Ethnology,

London School of Economics, University of London.

\section{Solubility of Phosphates in Relation to Hydrogen Ion Goncentration.}

WITHIN the last few years statements have appeared in various journals giving the $\mathrm{P}_{\mathrm{H}}$ values at which certain salts yield precipitates upon being rendered less acid. Some of these also record the lower limit of acidity at which precipitation is said to be complete. It accordingly appeared to be of interest to determine the form of the solubility curve. This was done for certain phosphates, using samples purchased as pure and washed with distilled water repeatedly to remove traces of more soluble phosphates, etc. The determinations were made at air temperature, about $10-12^{\circ} \mathrm{C}$., upon solutions cleared by the centrifuge, using the cœruleo-molybdate reaction of Denigès. Nine determinations were made upon a sample of tricalcic phosphate (B.P.), between $\mathrm{P}_{\mathrm{H}} 7^{\circ} \mathrm{O}$ and $\mathrm{P}_{\mathrm{H} 5} \cdot \mathrm{I}$, hydrochloric acid being used to increase the acidity.

Over this range the solubility increased from II4 to 786 parts per million. When $\mathrm{P}_{\mathrm{H}}$ values are taken as ordinates (the higher values being at the bottom of the paper) and concentrations as abscissæ, the nine points give a curve which at first ascends steeply and then becomes more nearly parallel to the concentration axis; thus a small change in the $P_{H}$ value is accompanied by a large change in solubility. Accordingly the precise $P_{H}$ value at which a precipitate is first obtained depends on the concentration of the phosphate and precipitation is never absolutely complete with the pure salt, even at $\mathrm{P}_{\mathrm{H}} 7^{\circ} \mathrm{O}$. The phosphates of strontium and of barium give curves which are qualitatively similar. The phosphate of magnesium is more soluble $45^{\circ}$. p.p.m. at $\mathrm{P}_{\mathrm{H}} 7 \cdot 7$, and the curve rises somewhat less sharply at the start; it reaches the value $I 233$ p.p.m. at $\mathrm{P}_{\mathrm{H}} 5 \cdot 8$.

$\mathrm{CaHPO}_{4}$ is much more soluble than $\mathrm{Ca}_{3}\left(\mathrm{PO}_{4}\right)_{2}$, and the solubility of the latter is increased if it contain any of the former as an impurity. $\mathrm{CaH}_{4}\left(\mathrm{PO}_{4}\right)_{2}$ was found to dissolve readily, a slight deposit only being left; this does not appear to be the original salt. The reaction given by the sample used was markedly acid, $\mathrm{P}_{\mathrm{H}} 3 \cdot 6$.

$$
\text { No. } 2860 \text {, VOL. I I } 4]
$$

The phosphates of lead and zinc were found to be highly insoluble, lead only giving phosphate equivalent to 0.97 p.p.m. of $\mathrm{P}_{2} \mathrm{O}_{5}$ at $\mathrm{P}_{\mathrm{H}} 6.75$ and zinc I. II at $\mathrm{P}_{\mathrm{H}} 6 \cdot 85$, nickel follows with $\mathrm{x} \cdot 9$ at $\mathrm{P}_{\mathrm{H}} 8 \cdot 9$. The readily hydrolysed ferrous and ferric phosphates appear to have solubility minima in the acid region, and the addition of alkali to bring the solutions to neutrality results in more phosphate becoming available in solution. These relations, being of importance in studies on plant nutrition, are being worked out, and it is hoped that the results may be published in more complete form within a year.

Marine Biological Lảboratory, Plymouth, July I6.

$$
\text { W. R. G. Atrkins. }
$$

\section{The Phosphide Eutectic in Cast Iron.}

THE accompanying photomicrograph (Fig. I) shows the phosphide eutectic in a grey cast iron at 5000 diameters. This shows that the constituent which appears as dark markings at $\times 1000$, and is still commonly described as iron carbide, is actually duplex, and in fact very similar to pearlite, consisting of alternate laminæ of iron carbide and iron.

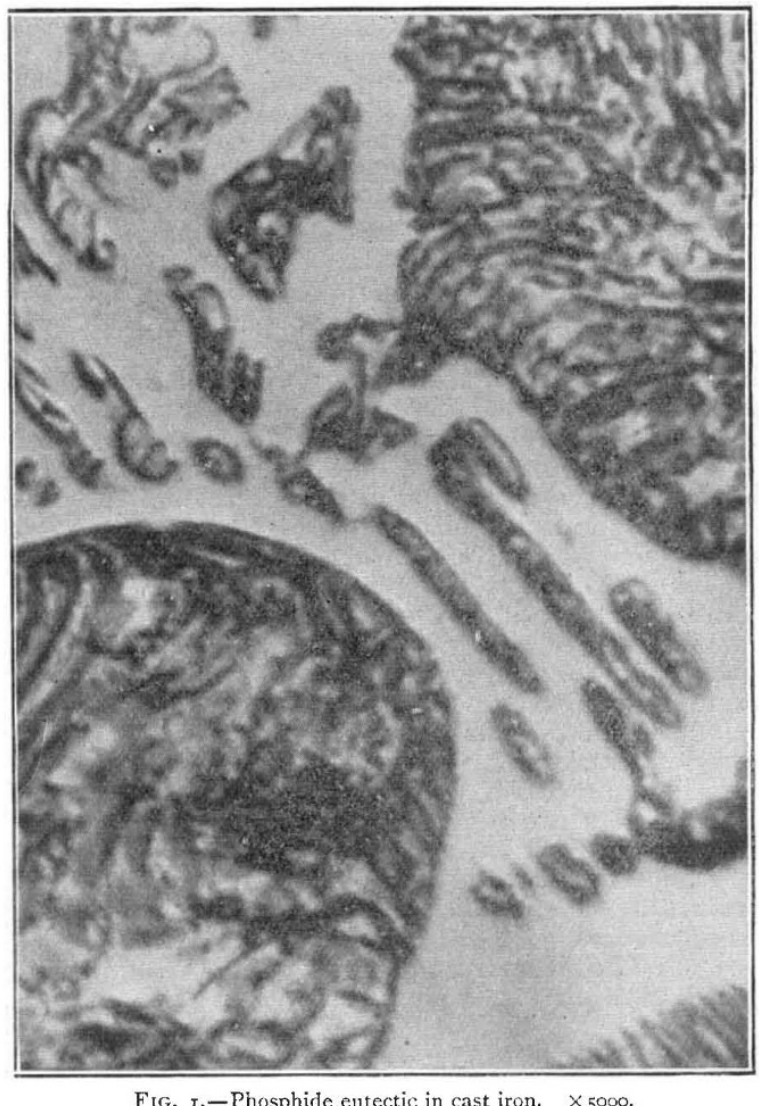

It is recognised from the research of Stead that there wouid be present the three constituents of the triple eutectic, namely, iron phosphide, iron carbide, and austenite, or their transition products. Thus the presence of laminated pearlite, from the transformation of austenite, is accounted for. The pearlite thus associated structurally within the phosphide masses may conceivably be richer (it probably is, but may even be poorer) in carbon content than obtains in the normal pearlite ratio, $\mathrm{Fe}_{3} \mathrm{C}_{2} \mathrm{IFe}$. Prof. Desch, 